\title{
USE OF SLOW STRAIN RATE TENSILE TESTING TO ASSESS THE ABILITY OF SEVERAL SUPERALLOYS TO RESIST ENVIRONMENTALLY-ASSISTED INTERGRANULAR CRACKING
}

\author{
Tim P. Gabb ${ }^{1}$, Jack Telesman ${ }^{1}$, Anthony Banik ${ }^{2}$, Erin McDevitt ${ }^{2}$ \\ 1 NASA Glenn Research Center; \\ 21000 Brookpark Rd., Cleveland, Ohio 44135, USA \\ 2 ATI Allvac; \\ 2020 Ashcraft Ave, Monroe, NC 28110 , USA
}

Keywords: Disk, environment, intergranular, tensile, fatigue

\begin{abstract}
Intergranular fatigue crack initiation and growth due to environmental degradation, especially at notched features, can often limit the fatigue life of disk superalloys at high temperatures. For clear comparisons, the effects of alloy composition on cracking in air needs to be understood and compared separately from variables associated with notches and cracks such as effective stress concentration, plastic flow, stress relaxation, and stress redistribution. The objective of this study was to attempt using simple tensile tests of specimens with uniform gage sections to compare the effects of varied alloy composition on environment-assisted cracking of several powder metal and cast and wrought superalloys including ME3, LSHR, Udimet 720TM, ATI 718 Plus ${ }^{\circledR}$ alloy, Haynes $282^{\mathrm{TM}}$, and Inconel $740^{\mathrm{TM}}$. Slow and fast strain-rate tensile tests were found to be a useful tool to compare propensities for intergranular surface crack initiation and growth. The effects of composition and heat treatment on tensile fracture strain and associated failure modes were compared. Environment interactions were determined to often limit ductility, by promoting intergranular surface cracking. The response of various superalloys and heat treatments to slow strain rate tensile testing varied substantially, showing that composition and microstructure can significantly influence environmental resistance to cracking.
\end{abstract}

\section{Introduction}

The increase in the operating temperatures of nickel-based turbine disk components in the new generation of high performance gas turbine engines has placed additional emphasis on the dwell fatigue-environment interactions which can significantly reduce the fatigue crack initiation and propagation lives of disk components at high temperatures $[1,2]$. The major cause of the reduction in structural capabilities of these components under dwell fatigue conditions is the susceptibility of this class of materials to environmental degradation. While there is much debate and ongoing work regarding the detailed microstructural electro-chemical mechanisms which are responsible for environmental damage, it is widely accepted that intergranular crack initiation and propagation are the manifestations of environmental attack in superalloys $[1,3,4,6,7]$ at temperatures of $650{ }^{\circ} \mathrm{C}$ and higher. Since the strength of the grain boundaries and the magnitude of local imposed stresses play a major role in controlling dwell fatigue behavior, complex elastic-viscoplastic factors which influence stress concentration, stress relaxation, and stress redistribution come into play. 
In-depth studies of the dwell fatigue environment interactions are typically time- consuming and costly due to the utilization of complex test geometries to simulate notch stress redistributions and the requirement to perform long lasting dwell crack growth testing. While these tests are still required for detailed studies, other low cost alternative tools need to be developed to produce reliable data regarding the susceptibility of various superalloy compositions and heat treatments/microstructures to environmental degradation. One possible approach in the development of such a tool is the determination of the extent of intergranular crack initiation and propagation under conditions of interest. The frequency of intergranular surface cracking has been observed to increase with test temperature in monotonic tensile and creep tests, as well as in low cycle fatigue tests without or with dwells $[2,8]$. Such simple tests might therefore be useful to isolate the influences of varied superalloy microstructure and composition on such surface cracking.

The power and the petro-chemical industries have utilized slow-strain rate tensile tests in corrosion studies to determine the materials susceptibility to environment-assisted cracking [9]. The rationale for this approach is to perform accelerated tests while attempting to simulate environmental and loading conditions of interest. The slow strain rate tensile testing allows sufficient time for materials susceptible to environmental attack to exhibit degradation, which is measured by changes in mechanical properties such as elongation or reduction in area. Utilizing this approach may offer a low cost tool to screen superalloys for environment-assisted intergranular surface cracking in air which is of interest for aerospace gas turbine applications.

The need to assess and improve dwell fatigue behavior of powder metallurgy (PM) and cast and wrought $(\mathrm{CW})$ gas turbine disk alloys has led to the current program, in which new generation disk alloys are evaluated and compared to cast and wrought superalloys specifically developed for use in the power and petro-chemical industries to withstand demanding corrosion and oxidation conditions. Those demanding conditions have required compositions and microstructure phases highly resistant to oxidation and corrosion attack. Inconel 718 was adopted and optimized for such applications [10], and ATI 718Plus ${ }^{\circledR}$ alloy [11] may also have potential for such applications. Inconel $740^{\mathrm{TM}}$ has been developed for demanding applications in the power generation industry [12]. Haynes $282^{\mathrm{TM}}$ has been developed for both land-based and aerospace turbine engines [13]. Due to their compositions, these alloys could be more resistant to environment-assisted surface crack initiation and propagation often observed in $\mathrm{P} / \mathrm{M}$ disk superalloys. Comparisons among these alloys could be useful for understanding their different properties, and how to then improve PM disk superalloys.

The objective of this study was to compare the effects of varied alloy composition and microstructure on environment-assisted cracking of several powder metal and cast and wrought superalloys using uniform gage specimens with simple loading cycles. Slow strain rate tensile tests were used to screen the various alloys and microstructures for tendencies to exhibit environmental degradation through intergranular crack initiation and crack growth, and reduction in tensile ductility. Companion tensile tests were performed at a very fast strain rate for which no environmental degradation is expected to occur. The effects of microstructure and composition on tensile elongation and associated failure modes were then compared. 


\section{Materials and Procedures}

The compositions in weight percent of the tested materials are listed in Table I. Of the powder metal (PM) superalloys, the compositions of ME3 and LSHR had similar Cr, Al, and Ti levels, but bigger differences in $\mathrm{Mo}, \mathrm{Nb}, \mathrm{Ta}$, and $\mathrm{W}$ contents. Udimet 720 had significantly higher $\mathrm{Cr}$ and $\mathrm{Ti}$, and lower $\mathrm{Co}$ and $\mathrm{Al}$ contents. These alloys were consolidated from powder atomized in argon, then extruded and isothermally forged into disks. Blanks were extracted from the rim of fully heat treated ME3 disks [14] and the bore of a fully heat treated Udimet 720 disk [15], which each had been previously studied. Rectangular blanks of LSHR were extracted and separately heat treated. Published recommended heat treatments were applied for each alloy. Additional solution heat treatments were then added for LSHR which varied grain size and cooling rate.

Of the cast and wrought (CW) superalloys examined, ATI 718Plus alloy was obtained as a hot rolled and solution annealed $40 \mathrm{~mm}$ thick ring, while Haynes 282 and Inconel 740 were obtained as hot rolled and solution annealed plates $13 \mathrm{~mm}$ and $16 \mathrm{~mm}$ thick, respectively. These superalloys had increased $\mathrm{Cr}$ contents but often lower $\mathrm{Al}$ and $\mathrm{Ti}$ levels, compared to the PM superalloys. Blanks were extracted from these solution-annealed materials, and were heat treated as listed in Table II. Solution heat treatment temperatures and times were selected to obtain a mean linear intercept grain diameter near $50 \mu \mathrm{m}$ for each alloy, but otherwise followed manufacturer recommendations. Additional solution heat treatments were then added for ATI 718Plus alloy to vary grain size.

Table I. Compositions of alloys in weight percent.

\begin{tabular}{|c|c|c|c|c|c|c|c|c|c|c|c|c|c|c|c|c|c|c|}
\hline Alloy - wt \% & Al & $\mathrm{E}$ & $\mathrm{C}$ & $\mathrm{Co}$ & $\mathrm{Cr}$ & $\mathrm{Fe}$ & $\mathrm{Mn}$ & Mo & Ni & Nb & 0 & $S$ & $\mathrm{Si}$ & $\mathrm{Ta}$ & $\mathrm{Ti}$ & $\mathrm{V}$ & $W$ & $\mathrm{Zr}$ \\
\hline \begin{tabular}{|l|} 
LSHR \\
\end{tabular} & 3.54 & 0.027 & 0045 & 20.40 & 12.30 & 0.068 & 0.001 & 2.71 & $\mathrm{Ba}$. & 1.49 & 0.018 & $<001$ & 0.012 & 1.52 & 3.45 & 0006 & 4.28 & 0.049 \\
\hline ME3 & 3.40 & 0.025 & 0.050 & 20.70 & 12.8 & & & 3.80 & $\mathrm{Ba}$. & 0.9 & & $<.001$ & & 2.30 & 3.70 & & 2.00 & 0.05 \\
\hline Udimet 720 & 2.52 & 0.019 & 0025 & 146 & 163 & 0.05 & & 298 & $\mathrm{Bal}$ & & 0001 & $<001$ & $<010$ & & 505 & & 131 & 0.03 \\
\hline ATI 718Plus & 145 & 0.002 & 0.022 & 8.88 & 17.94 & 9.36 & 0.05 & 2.66 & $\mathrm{Ba}$, & 5.39 & $<001$ & $<001$ & 0.05 & & 072 & 0.012 & 0.94 & 0.008 \\
\hline Haynes 282 & 1.57 & 0.001 & 0.057 & 9.86 & 19.49 & 0.25 & 0.03 & 8.08 & $\mathrm{Bal}$ & & $<.001$ & 5.001 & 0.04 & & 196 & & & \\
\hline Incanel 740 & 0.91 & & 0.028 & 19.84 & 24.31 & 0.42 & 0.24 & 0.47 & $\mathrm{Ba}$. & $\{.95$ & $<.001$ & 5.001 & 0.48 & & 1.87 & & & 0.02 \\
\hline
\end{tabular}

Tensile and fatigue crack growth specimens were machined using low stress grinding procedures, with the gage sections finally polished parallel to the loading direction, in order to not exceed $0.21 \mu \mathrm{m}$ average roughness. Tensile specimens were machined with a nominal gage diameter of $4.1 \mathrm{~mm}$ across a gage length of $21 \mathrm{~mm}$. Fatigue crack growth specimens were machined with a rectangular gage section $10 \mathrm{~mm}$ wide and $4.3 \mathrm{~mm}$ thick. A surface flaw was introduced by electro-discharge machining on one side of the gage section a flaw about 0.356 $\mathrm{mm}$ wide and $0.178 \mathrm{~mm}$ deep.

Slow strain rate tensile tests described in ASTM G129-00 have been often used to investigate the effects of aggressive environments on tensile elongation [16]. This test was adapted here to screen the effects of air environment on activating intergranular crack initiation and growth. "Slow" tensile tests were performed at $704{ }^{\circ} \mathrm{C}$ with a displacement rate of $0.0017 \mathrm{~mm} / \mathrm{s}$ and average strain rate near $8.3 \times 10^{-5} \mathrm{~s}^{-1}$. "Fast" tensile tests were also performed, with a very fast displacement rate of $15 \mathrm{~mm} / \mathrm{s}$, which produced an average strain rate near $0.7 \mathrm{~s}^{-1}$, but with other procedures in general accordance with ASTM E21-09. At the very fast strain rates employed, all the specimens failed in less than $0.4 \mathrm{~s}$, while the slow strain tests lasted anywhere from 5 minutes to one hour, depending on the strain at failure, which varied and is discussed in detail later. These fast tensile tests were used to identify tensile failure modes operative with minimal time for environmental interactions during loading. 
Table II. Specimen Heat Treatments and Tensile Test Results.

\begin{tabular}{|c|c|c|c|c|c|c|c|c|c|}
\hline Alloy & $\begin{array}{c}\text { Tensile } \\
\text { Specimen ID }\end{array}$ & $\begin{array}{l}\text { Solution Heat } \\
\text { Treatment }\end{array}$ & $\begin{array}{c}\text { A.ging Heat } \\
\text { Treatment }\end{array}$ & $\begin{array}{c}\text { Grain } \\
\text { Size- } \\
\text { umm } \\
\end{array}$ & $\begin{array}{c}\text { Displace } \\
\text { ment } \\
\text { Fiate - } \\
\text { moms } \\
\end{array}$ & 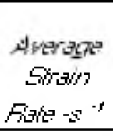 & $\begin{array}{c}\text { Ullimate } \\
\text { Strength - } \\
\text { MPa }\end{array}$ & $\begin{array}{l}\text { Inelastic } \\
\text { Fracture } \\
\text { Strain } \% \\
\end{array}$ & $\begin{array}{c}\begin{array}{c}\text { Feductio } \\
\text { n in Area } \\
\%\end{array} \\
\end{array}$ \\
\hline LSHR & $\mathrm{T} 3-\mathrm{T} 1 \mathrm{~A}$ & $1171 \mathrm{G} 2 \mathrm{k}$ 72Сpm & $855[14 h+775$ CI8h & \begin{tabular}{|l|l|}
15 \\
\end{tabular} & 0.0017 & $\varepsilon \mathbb{Z}_{a}$ & 1220 & 14.4 & 22.7 \\
\hline LSHA & $\mathrm{T} 2-\mathrm{T} 5$ & 1171마각ㄹㄷп & 855다4hา+775당า & 15 & 0.0017 & 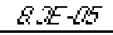 & 1370 & 14.3 & 20.1 \\
\hline LSHR & ZE-T2D & 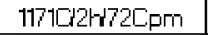 & $855[14 h+775[18 h$ & 15 & 14 & $\varepsilon \not E-\not t$ & 1435 & 12.3 & 24.4 \\
\hline LSHF & P'3-9FC2-4 & 1171С2-1202Српи & 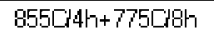 & 15 & 0.0017 & 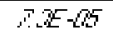 & 1218 & 8.6 & 12.4 \\
\hline LSHR & P3-10FC2-1 & 1171 1C2t202С-pm & $855[14 h+775$ CI8h & 15 & 0.0017 & , E- & 1284 & 6.6 & \\
\hline LSHR & $\mathrm{P3}-10 \mathrm{FC} 2-4$ & 1171С2r-1202Сpm & 855CI4h +775Ci8h & 15 & 0.0017 & $\therefore 4 E-6$ & 1227 & 9.6 & 139 \\
\hline LSHR & F3-10FC2-2 & $1171 \mathrm{Cl} 2 \mathrm{r} 202 \mathrm{Cpm}$ & $855[14 h+775 \mathrm{C}$ (8) & 15 & 14 & $G A E O$ & 1510 & 12.5 & 22.8 \\
\hline LSHF & P3-37F3 & 1135С-12h72Cpm & 855[14h+775닥 & 7 & 0.0017 & $g a \infty$ & 1172 & 138 & 16.1 \\
\hline LSHR & $\mathrm{P3}-38 \mathrm{~F} 3$ & 1135CI2H72Cpm & 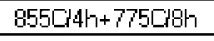 & 7 & 0.0017 & $\therefore \&$ & 1144 & 13.1 & 14.0 \\
\hline LSHP & P3-37F4 & 1135Cl2h/2Cpm & $855[14 h+775[18 h$ & 7 & 14 & $\theta \mathbb{E}-O$ & 1449 & 15.7 & 24.9 \\
\hline LSHF & 27-R1A & 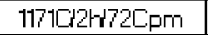 & 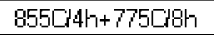 & 50 & 0.0017 & $\operatorname{RaE}-\mathrm{B}$ & 1210 & 17.3 & 26.9 \\
\hline LSHP & $T 4-[4$ & 1171С22-v72Сpm & 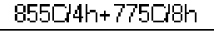 & 50 & 0.0017 & 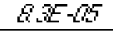 & 1161 & 20.4 & 20.0 \\
\hline LSHR & $\mathrm{T} 4-30 \mathrm{FC} C 2-1$ & 1171C가-1202Сpm & 855[-14h+775CI8h & 50 & 0.0017 & $\therefore=6$ & 1253 & 8.2 & 12.4 \\
\hline MES & S107-SRW/3 & 11710111798-pm & 843ㄱㄴㄱㄱ +760CI8h & 35 & 0.0017 & $g E \theta$ & 1179 & 17.4 & 38.8 \\
\hline WE3 & H111-SRA1 & 1171011-1106:сргп & 843긴า +760 CI8h & 35 & 0.0017 & $g a E-\infty$ & 1306 & 14.8 & 26.9 \\
\hline $\mathrm{ME} 3$ & VML51-ASGC & 1171삭-172С-рm & 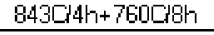 & 35 & 14 & $\therefore 2-O H$ & 1409 & 12.6 & 23.9 \\
\hline ME3 & S101-SPR1* & 1171С11-179Сеm & 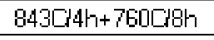 & 35 & 0.0017 & $g D E-\alpha$ & 1128 & 22.9 & \\
\hline ME3 & S107-SRFi" & 1171С11179С-рm & 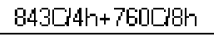 & 35 & 0.0017 & $\operatorname{saE}-6$ & 1145 & 22.0 & \\
\hline$\bigsqcup 720$ & ᄂ.345-1 & 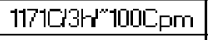 & 7601818h+650CI24h & 45 & 0.0017 & 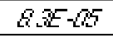 & 1128 & 19.2 & 32.5 \\
\hline$\bigsqcup 720$ & U345-4 & $1171 \mathrm{Ci} 3 \mathrm{k} \mathrm{r}^{\prime 100 \mathrm{Cpm}}$ & $760 \mathrm{C} / \mathrm{g}+650 \mathrm{C} 24 \mathrm{~h}$ & 45 & 0.0017 & $\sin \theta$ & 1092 & 24.9 & 36.0 \\
\hline 1720 & ป345-2 & $1171 \mathrm{Cl} 3 \mathrm{k} \mathrm{r}^{\prime \prime 100 \mathrm{CPm}}$ & 760C19h+650C24h & 45 & 14 & $5 \&$ & 1365 & 10.7 & 17.5 \\
\hline ATI718Flus & $A H 1 E-A$ & $954 \mathrm{C} 11 \mathrm{~h} 72 \mathrm{Cpm}$ & 788Cish +704Cildh & 16 & 0.0017 & $\therefore Q E$ & 1011 & 7.1 & 15.3 \\
\hline ATI718Flus & AHIE-D & 954С11172Cpm & 788딩า +704믹 & 16 & 0.0017 & $a g E-\alpha$ & 1010 & 10.2 & 14.3 \\
\hline ATI718Flus & $A H 1 E-[C$ & 954С11172Сpm & 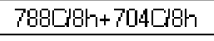 & 16 & 14 & 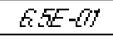 & 1195 & 14.5 & 27.3 \\
\hline ATI718Flus & AR2-T1 & & & 15 & 0.0017 & $Q A E-C$ & 1026 & 27.8 & 77.7 \\
\hline ATI718Flus & $\mathrm{AF} 1-\mathrm{T} 2$ & & & 15 & 14 & 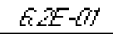 & 1240 & 12.4 & 35.9 \\
\hline ATI718Flus & $\mathrm{AH} H \mathrm{OE}-\mathrm{A}$ & $1025 \mathrm{Cl} 0.5 \mathrm{r} 7 \mathrm{C} \mathrm{Cpm}$ & 788깅ำ+704C18h & 55 & 0.0017 & $Q 4 E-Q$ & 913 & 5.2 & 63 \\
\hline ATI718Plus & $\mathrm{AH} 2 \mathrm{TS}-\mathrm{B}$ & $1025 \mathrm{C} 10.5-172 \mathrm{Cpm}$ & 788Cighn+704Cigh & 55 & 0.0017 & $a, Q$ & 902 & 4.7 & 95 \\
\hline ATI718Flus & $\mathrm{AH} 10 \mathrm{E}-\mathrm{B}$ & $1025 \mathrm{Ci} 0.5-172 \mathrm{Cpm}$ & 788당ำ+704다으 & 55 & 14 & 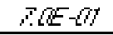 & 1078 & 21.0 & 49.6 \\
\hline ATI718Plus & $\mathrm{AH} 2 \mathrm{TS}-\mathrm{A}$ & 1025С10.5-172Сpm & 789[18h+704객 & 55 & 14 & $\therefore X-\partial t$ & 1072 & 21.0 & 48.9 \\
\hline Haynes 282 & 282-EL6E-1 & $1135 \mathrm{C} 10 \mathrm{~m} / 2 \mathrm{C} \mathrm{pm}$ & $1010 \mathrm{Cl} 2 \mathrm{~h}+789 \mathrm{C} / \mathrm{h}$ & 55 & 0.0017 & $Q A E-Q B$ & 903 & 17.7 & 21.3 \\
\hline Haypes 282 & $\mathrm{HL}-W B E-A$ & 1135C10 $\mathrm{m} 72 \mathrm{Cpm}$ & $1010 \mathrm{C} / 2 \mathrm{~h}+798 \mathrm{C}$ - & 55 & 0.0017 & $B A E-\alpha$ & 876 & 16.0 & 20.3 \\
\hline Haypes 282 & 282-DW/gE-2 & $1135 \mathrm{C} 10 \mathrm{~m} / 2 \mathrm{C} \mathrm{pm}$ & $1010 \mathrm{Cl} 2 \mathrm{~h}+788 \mathrm{C} / \mathrm{h}$ & 55 & 14 & $\therefore \&-O t$ & 982 & 21.4 & 34.8 \\
\hline Inconel 740 & $740-W 2 E-1$ & $1149 \mathrm{C} 10 \mathrm{~m} 72 \mathrm{Cpm}$ & 800016h & 79 & 0.0017 & $Q 4 E-Q 5$ & 836 & 23.1 & 38.0 \\
\hline Inconel 740 & 740-Lla & & 8000116h & 79 & 0.0017 & $Q 4 E-Q b$ & 806 & 232 & 34.9 \\
\hline Inconel 740 & $740-W 2 \mathrm{E}-2$ & $1149 \mathrm{C} 10 \mathrm{~m} / 2 \mathrm{Cpm}$ & 8000it16h & 78 & 14 & r\& $O H$ & 969 & 19.4 & 33.0 \\
\hline
\end{tabular}

- vacLILm

Comparative slow tensile tests of ME3 were also performed in a vacuum chamber held at a vacuum pressure not exceeding $8 \times 10^{-6}$ torr, which was integrated into an electro-mechanical universal testing machine. These tests were used to inspect tensile failure modes operative in the slow strain rate tests without an air environment. Resistance-heating furnace elements were used to heat all specimens. No extensometer was attached to the specimens for strain measurements in the tensile tests, to avoid contacting the exposed surfaces.

Fatigue crack growth tests were performed at NASA GRC in general accordance with ASTM E647-08. Tests were performed in a closed-loop servo-hydraulic test machine using resistance heating and the potential drop technique for measurement of crack growth. Pre-cracking was performed at room temperature, then tests were performed at $704{ }^{\circ} \mathrm{C}$ using a maximum stress of $621 \mathrm{MPa}$, a minimum/maximum stress ratio of 0.05 , and dwell time of $90 \mathrm{~s}$ imposed at maximum stress in each cycle. The fracture surfaces of each tested specimen were subsequently analyzed to calibrate crack length versus potential drop.

Linear intercept grain sizes were determined from metallographically prepared sections using of circular grid overlays on optical images, in accordance with ASTM E112-10. These 
metallographic sections were swab etched with Waterless Kalling's etchant $5 \mathrm{~g} \mathrm{CuCl} 2+100 \mathrm{cc}$ $\mathrm{HCl}+100$ cc ethyl alcohol.

Fractography was performed using scanning electron microscopy (SEM), along with some additional optical macro imaging. In addition to the SEM and the optical images, three dimensional (3D) topographical analyses were performed using SEM stereo pairs analyzed by Alicona MeX@ software. The 3D analysis was primarily done using relatively low mag SEM images to ascertain the qualitative $3 \mathrm{D}$ topography.

\section{$\underline{\text { Materials }}$}

\section{Results and Discussion}

Typical optical images showing grain microstructures are given in Fig. 1, and grain sizes are tabulated in Table II. Grain sizes were purposefully varied from $7 \mu \mathrm{m}$ to $50 \mu \mathrm{m}$ in LSHR, and from $15 \mu \mathrm{m}$ to $55 \mu \mathrm{m}$ in ATI 718Plus alloy. The other alloys were tested at only one grain size The heat treated CW alloys Haynes 282 and Inconel 740 had more variability in grain size than the other CW and PM alloys.

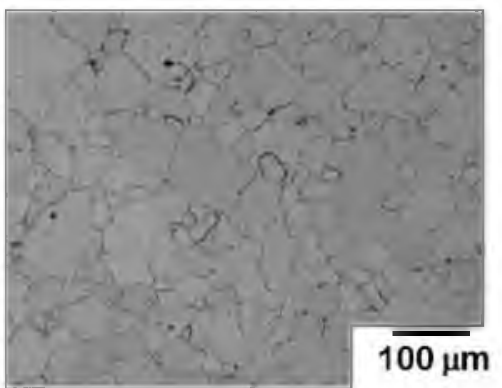

a)

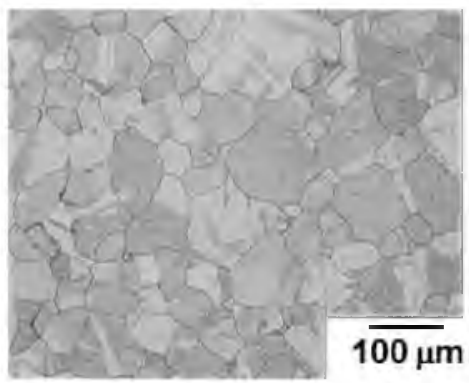

d)

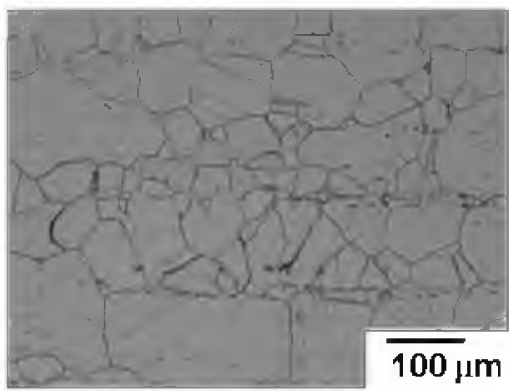

g)

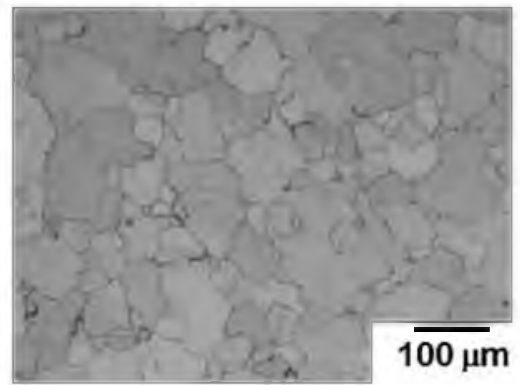

b)

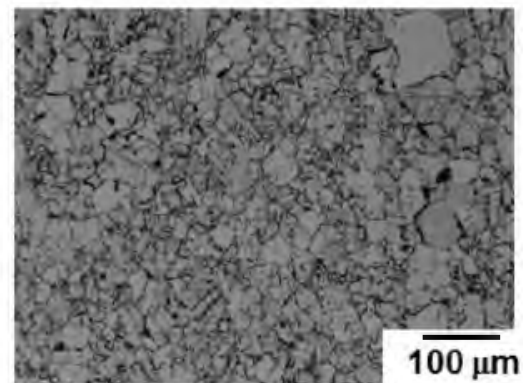

e)

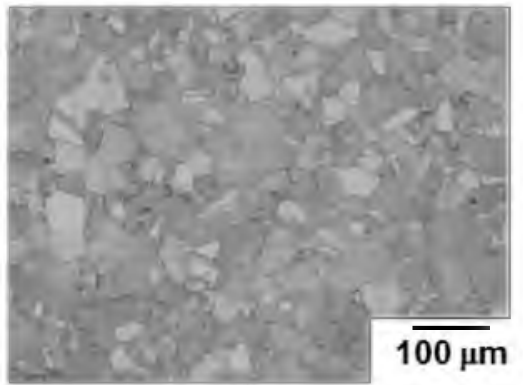

c)

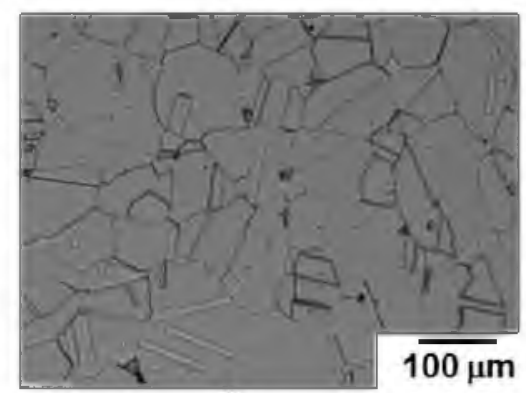

f)

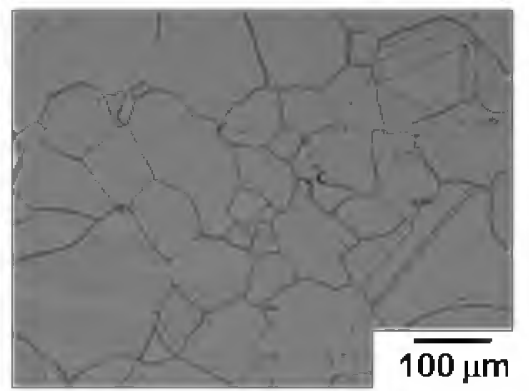

h)

Figure 1. Representative microstructures of alloys - grain sizes: a) LSHR - $15 \mu \mathrm{m}, \mathrm{b})$ LSHR $50 \mu \mathrm{m}, \mathrm{c}) \mathrm{ME} 3-35 \mu \mathrm{m}$, d) Udimet $720-45 \mu \mathrm{m}$, e) ATI 718Plus alloy fine grain - $16 \mu \mathrm{m}, \mathrm{f}$ ) ATI 718Plus alloy coarse grain (CG) - 55 $\mu \mathrm{m}$, g) Haynes $282-55 \mu \mathrm{m}, \mathrm{h}$ ) Inconel $740-78$ um. 


\section{$\underline{\text { Tensile Test Response }}$}

Typical fast tensile stress-strain curves of the materials process using their recommended heat treatments are compared in Fig. 2 a as dashed lines and summarized in Table II. Ultimate tensile strength was consistently higher for the fast tensile tests than for the slow tensile tests in all PM and $\mathrm{CW}$ alloys tested. The PM superalloys had higher strengths than the $\mathrm{CW}$ alloys in the fast tests. However, in these tests the $\mathrm{CW}$ alloys usually had higher inelastic fracture strains than the PM alloys. For all the alloys, the fracture strains in the fast tests were surprisingly high, ranging from 11 to $22 \%$. This indicated substantial plastic ductility was present in all the alloys.

Typical slow tensile stress-strain curves are also shown in Fig. 2 a as continuous lines and summarized in Table II. The PM superalloys again had higher strengths than the CW alloys in slow tests, yet they had similar inelastic fracture strains. Overall, fracture strains varied more widely among the alloys at slow strain rate, ranging from 7.1 to $24.9 \%$ when tested in air. The ME3 specimens tested in vacuum had significantly higher inelastic fracture strains than ME3 specimens tested in air. This indicated that the air environment did reduce inelastic fracture strain in these alloys.

Additional slow tensile tests were performed on LSHR for various heat treatment conditions, with solution temperature and cooling rate being varied to produce different grain sizes and grain boundary characteristics [7]. Such heat treatment variations had been found to strongly influence dwell fatigue crack growth rates of LSHR in past work. Stress-strain curves are compared for the different conditions in Fig. 2b. Inelastic fracture strain varied significantly in these slow tensile tests, with inelastic strain values as low as $8.2 \%$ associated with fast cooling rate. Fast cooling rates had previously been shown to increase dwell fatigue crack growth rates in both LSHR and ME3.

ATI 718Plus alloy was also evaluated with varied heat treatments. It was evaluated in the conditions of: 1) as-received (subsolvus solution anneal), 2) as-received plus an additional subsolvus solution anneal plus age, and 3) as-received plus an additional supersolvus solution anneal plus age, as detailed in Table II. While this is not a recommended heat treatment for ATI 718Plus alloy, it had been found in prior work [17] to produce fast dwell fatigue crack growth rates with very pronounced intergranular crack growth failure mode, and was reproduced so that a microstructure which is thought to produce extreme environmental embrittlement could be studied for comparison.

ATI 718Plus alloy tensile stress-strain curves and inelastic fracture strains are compared for the different conditions in Fig. 2c. The fine grain as-annealed condition gave the highest inelastic fracture strain measured of all materials tested, $27.8 \%$. However, inelastic strain was reduced to only $5.2 \%$ for the supersolvus solution heat treated material, which as mentioned earlier, exhibited very fast dwell crack growth in the previously performed study [16]. This result again suggested that slow tensile test response could be related to dwell fatigue crack growth resistance.

The fast tensile tests produced much smaller differences in fracture strains to failure, with all conditions showing excellent ductility 


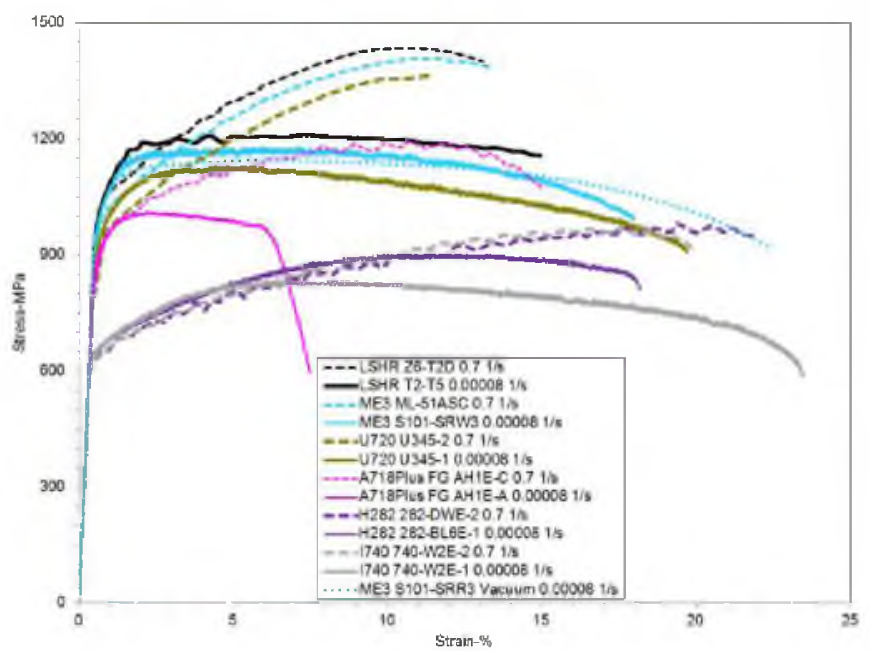

a)

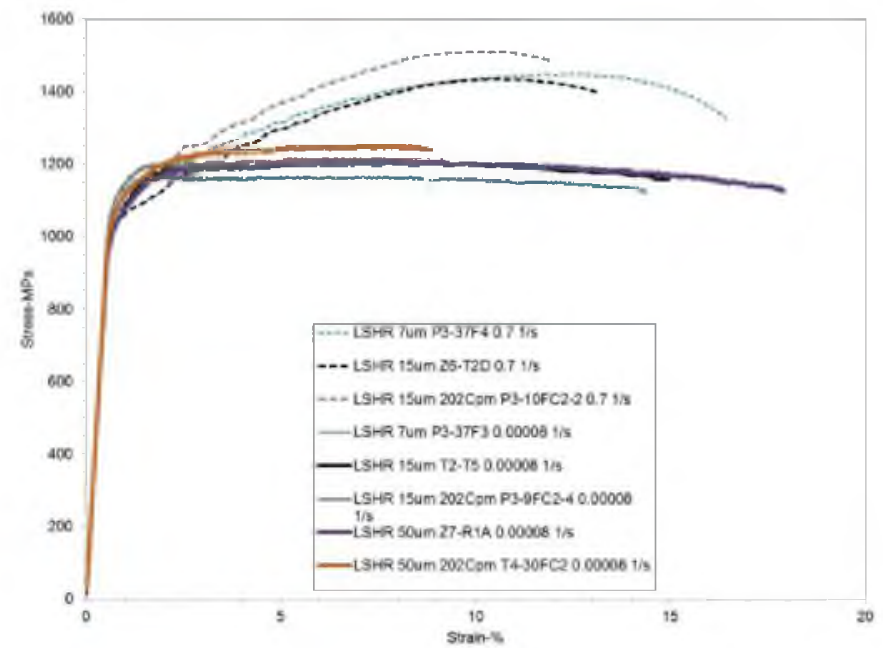

b)

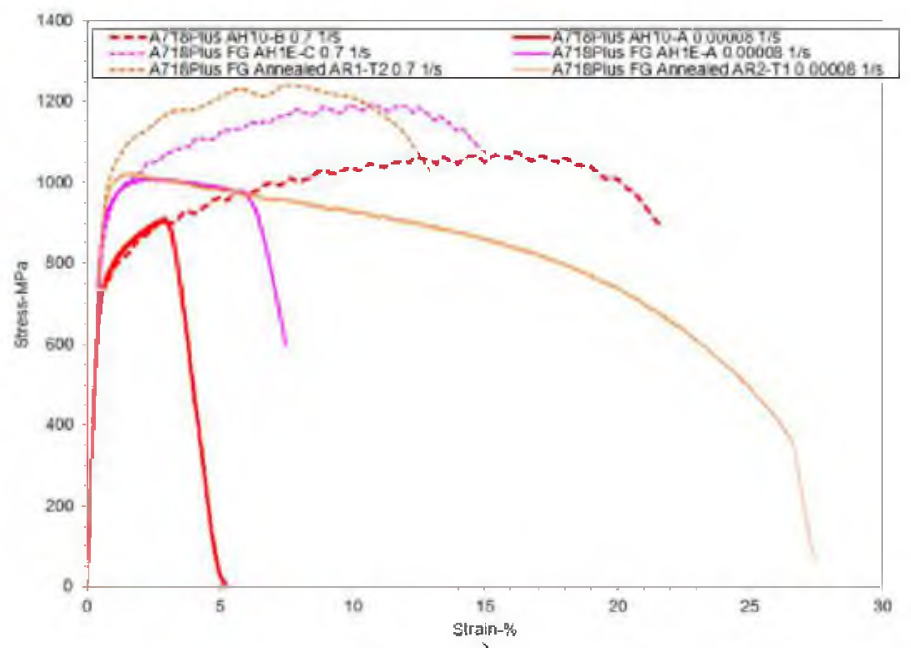

c)

Figure 2. Tensile stress-strain curves in fast and slow tensile tests for: a) recommended heat treatments, b) varied heat treatments of LSHR, c) varied heat treatments of ATI 718Plus alloy. 


\section{Tensile Failure Modes}

Fast Tensile Failures While the fracture morphology varied somewhat among the various fast tensile tests, none of the specimens exhibited any indication of environmentally induced failure mechanisms. Many of the specimens on the macro scale failed through a classical cup and cone failure, Fig. 3a. For all these specimens, both in the shear lip region as well as the mid-thickness failure regions perpendicular to the loading direction the failure mechanism consisted primarily of ductile microvoid coalescence. For other fast tensile tests of coarse grain ATI 718Plus alloy and Inconel 740, the failure occurred primarily through a $45^{\circ}$ shear mechanism, as shown in Fig. $3 \mathrm{~b}$. For both of these specimens microvoid coalescence was also the primary micro-deformation mode.

The failure appearance for two other fast tensile tests was somewhat different than those already described. Udimet 720 exhibited a small circumferential shear lip around the surface perimeter, Fig. 3c. Most of the internal fracture surface had a macroscopically tortuous appearance, while higher magnifications revealed this region to consist of crystallographic faceted areas joined together by regions which experienced tearing by microvoid coalescence. Haynes 282 specimen also exhibited a very tortuous failure with shear lips present near the surface. One small nearsurface region exhibited what at low magnifications appeared to be an intergranular failure, however at higher magnifications it became clear that the failure was highly ductile exhibiting both extensive slip bands and formation of microvoids.
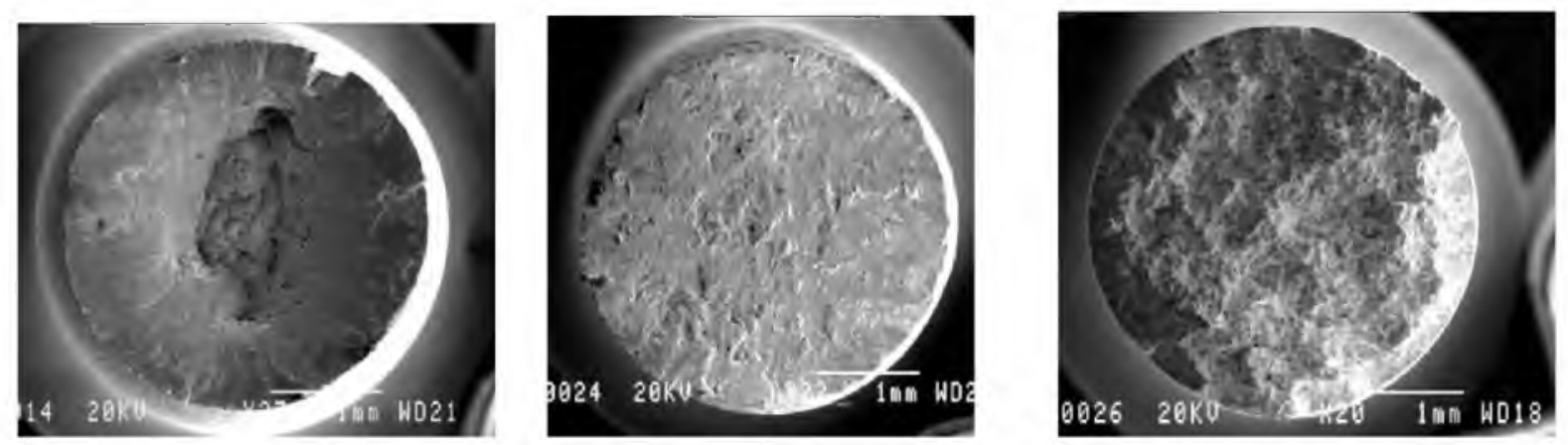

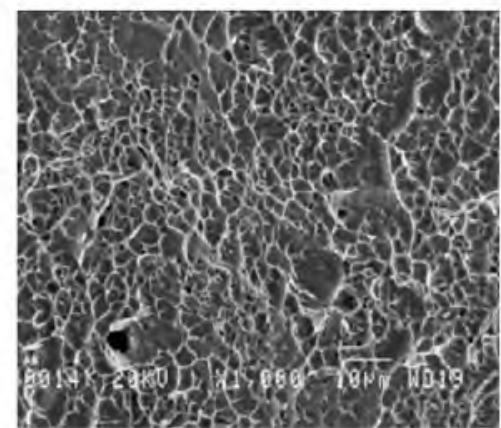

a)

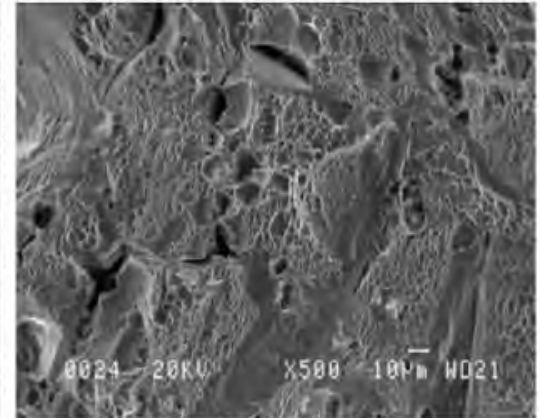

b)

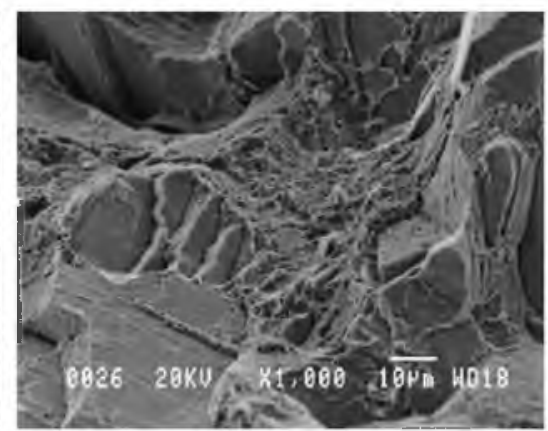

c)

Figure 3. Typical failures in fast tensile tests of: a) ATI 718Plus alloy as-annealed, b) Inconel 740, c) Udimet 720 .

Thus, while the extent of ductile tensile failure varied somewhat between the different fast tensile specimens, all of them exhibited regions of ductile failure by microvoid coalescence. The only specimen which exhibited substantial regions of non-ductile failure was the Udimet 720 specimen which revealed significant regions of crystallographic cracking. The duration of a fast 
tensile test is less than a $0.4 \mathrm{~s}$ from application of the load to failure. Thus the lack of intergranular failure mode and the presence of either ductile or crystallographic failure modes are confirmations that environmental failure did not play a role in the deformation process. Thus these tests do indeed represent a baseline of the active failure modes not influenced by either environment or visco-plastic behavior and thus can be used for comparison to the slow tensile test observed failure modes.

Slow Tensile Failures The slow tensile tests in air were performed to identify alloys which are susceptible to environmental attack by exhibiting surface crack initiations and intergranular crack growth. Both surface and internal failure regions were examined. The fractographic examination of the slow tensile tests revealed a wide range of active failure modes occurring among the different alloys, microstructures and heat treatments evaluated. The failure behavior can be grouped into four categories.

1) Tested specimens which showed extensive environmental degradation and for which the environmental attack played a primary role in the failure process.

2) Tested specimens which exhibited limited regions of environmental degradation, however their presence was highly significant since the main crack causing failure originated in these embrittled areas.

3) Tested specimens which exhibited limited environmental degradation and for which this degradation was a secondary failure mechanism not controlling the primary failure mode.

4) Tested specimens for which no environmental degradation was detected.

The most extensive environmental attack among all the specimens tested was exhibited by ATI 718 Plus alloy having a coarse grain size of $55 \mu \mathrm{m}$. As shown in Fig. 4a, a majority of the slow tensile fracture surface consists of an intergranular failed surface. Extensive secondary intergranular cracking is also present on the fracture surface. This dominant brittle intergranular failure mode for the slow tensile test differs radically from the previously described fast tensile test of this material which failed through ductile microvoid coalescence.

Another case where extensive intergranular surface cracking was observed for the slow tensile test of ATI718Plus FG, given a fine grain solution heat treatment of $954{ }^{\circ} \mathrm{C}$ for $1 \mathrm{~h}$ followed by cooling at $72{ }^{\circ} \mathrm{C} / \mathrm{min}$ and the standard aging heat treatment. It had a similar extensive region of brittle intergranular crack growth which occurred prior to the final failure. The final failure itself consisted of ductile microvoid coalescence occurring on a shear plane which is similar to the failure mode during the fast tensile test.

Falling into the second group are the tests conducted on the powder metal superalloys ME3 and LSHR, Fig. 4b. In both cases the region of intergranular surface initiation and intergranular propagation is rather limited but the main crack which led to the final failure originated from these environmentally degraded areas. Further evidence that the intergranular surface crack initiation and propagation are due to environmental degradation is illustrated in Fig. 4c, which shows the fracture morphology of an ME3 slow tensile test performed in vacuum. As opposed to the two slow tensile ME3 tests performed in air, the failure of the vacuum tested specimen initiated in the mid thickness region and consisted mostly of the ductile microvoid coalescence mechanism.

Falling into the third category of slow tensile tests which exhibited limited regions of environmental embrittlement, but for which these embrittled regions did not play a significant role in the primary failure causing mechanism was Udimet 720 , Fig. 4d. For Udimet 720, the 
300 micron diameter embrittled region is also not the origin of the final failure. The primary final failure mechanism in Udimet 720 is a combination of microvoid coalescence and crystallographic failure, and thus was very reminiscent of the failure mode of the fast-tested Udimet 720 .

Haynes 282 had transitional behavior between categories 2 and 3. It had larger regions of intergranular cracking than Udimet 720 , extending in from the surface. Yet, these regions were not connected, and not co-planar with the final ductile fracture.

For two other materials subjected to slow tensile tests, no environmentally embrittled regions were identifiable, Fig. 5. As-annealed fine grain ATI 718Plus alloy showed very extensive plastic deformation which was manifested by extreme necking in the gage section. As also shown here, the fracture surface itself consisted of relatively large plasticity induced microvoids. Thus, for this condition the slow tensile test produced extensive visco-plastic deformation, suggesting that thermally activated deformation mechanisms played an important role during failure. The Inconel 740 fracture surface was more highly tortuous than the other materials. Crystallographic shear of grains and microvoid coalescence were observed throughout the fracture surface. However, no clear embrittled regions of intergranular failure were observed. 

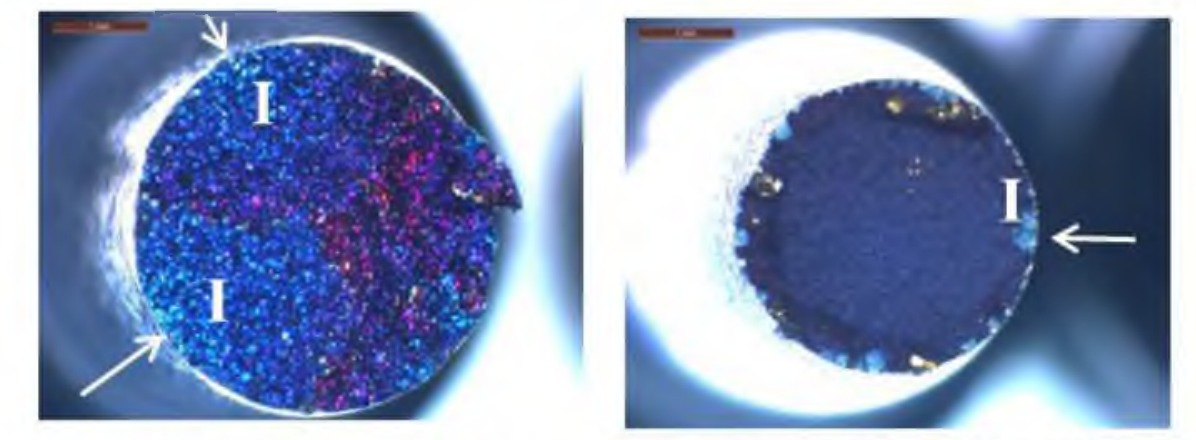

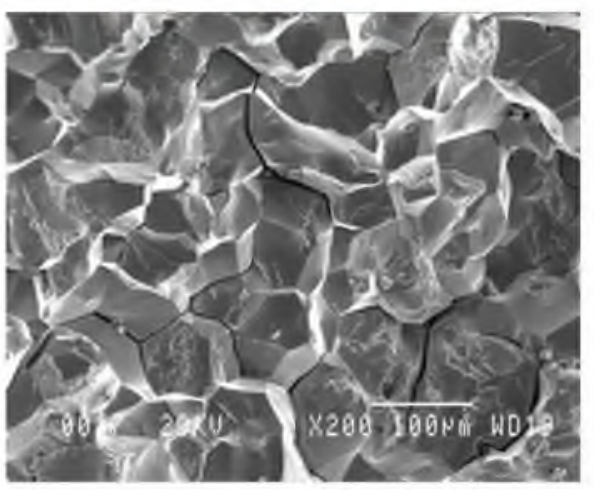

a)
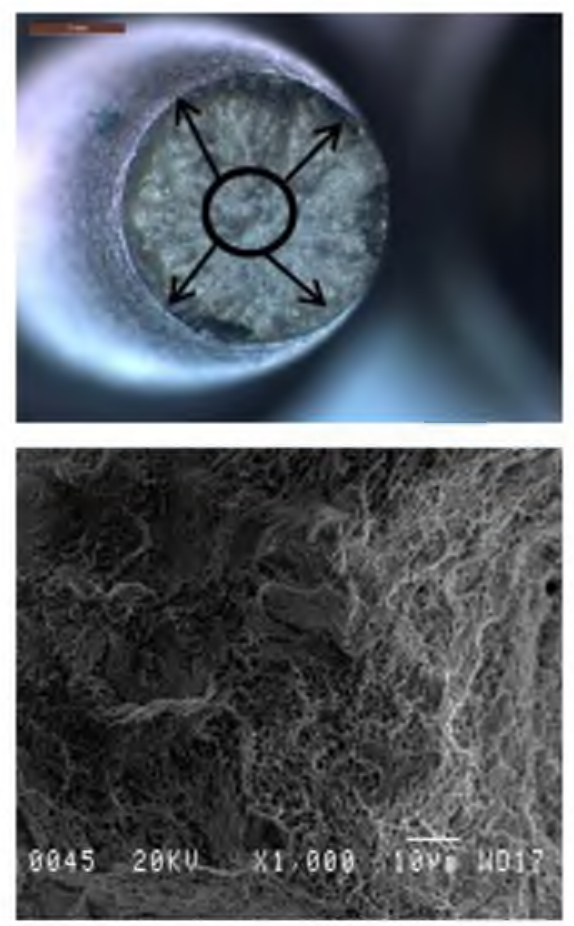

c)

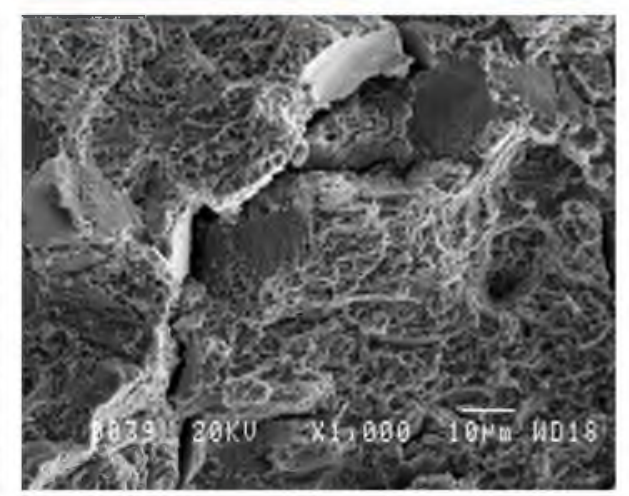

b)
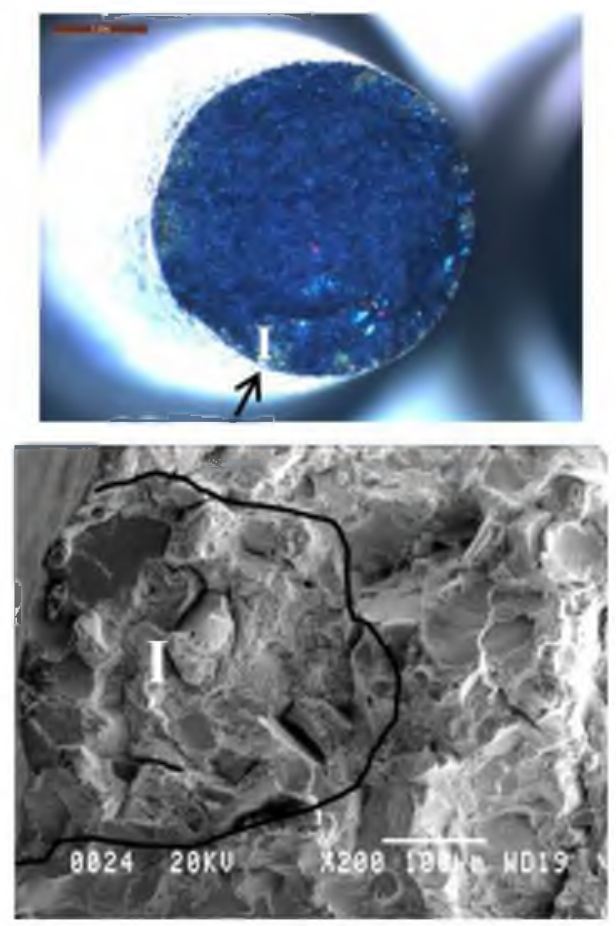

d)

Figure 4. Typical failures in slow tensile tests of: a) ATI 718Plus alloy coarse grain, b) ME3 tested in air, c) ME3 tested in vacuum, d) Udimet 720.

The differences in the failure mode response of the alloys tested using slow strain rate tensile methodology are most likely linked to the ability of the given alloy composition, heat treatment, and the resulting microstructure to withstand environmental degradation. The response ranged from no apparent environmental degradation in Inconel 740 and annealed fine grain ATI 718Plus alloy to very brittle intergranular failure for coarse grain heat-treated ATI 718Plus alloy. It 
should be noted again that this microstructure was produced solely for research purposes and is not the standard microstructure recommended by alloy's manufacturer. However the widely varied failure mode response of ATI 718Plus alloy to slow strain rate testing points clearly to the importance of various grain boundary characteristics to the susceptibility of environmental attack. Even in cases such as the coarse grain LSHR and ME3, where the extent of the intergranular failure mode was rather limited, its presence in the crack initiation region suggests that environmental attack can lead to early failure by acting as a crack initiation event which causes the further propagation of the crack by other more ductile deformation mechanisms. The slow strain testing was sensitive enough to allow for differentiation between environmental degradation which was a primary contributor to failure (LSHR, ME3) and Udimet 720 and Haynes 282 for which the limited observed intergranular regions had only a secondary effect on the failure process. The superior resistance of Inconel 740 and fine grain annealed ATI 718 Plus was also demonstrated through the use of this testing methodology.
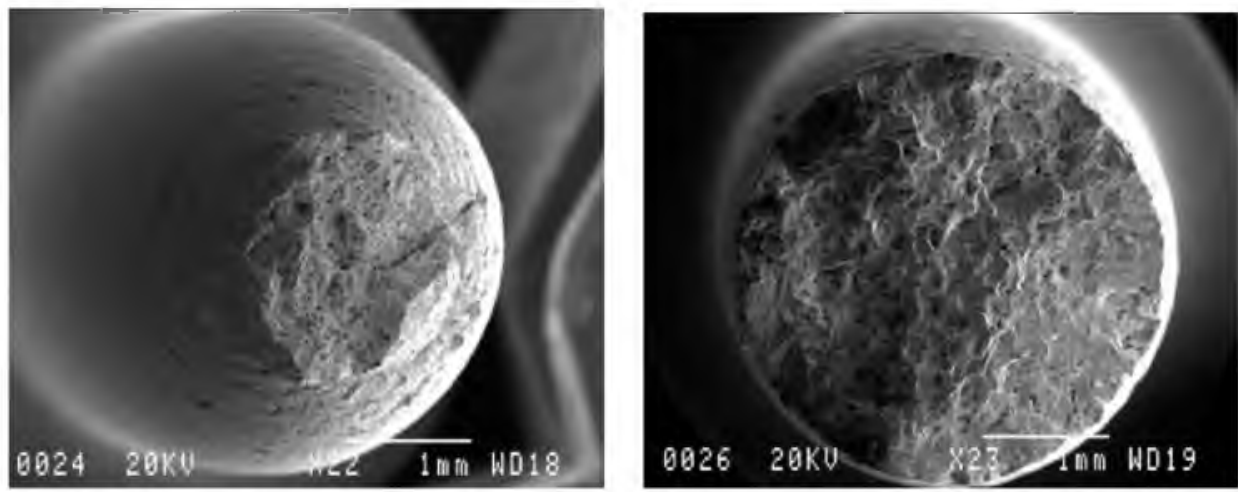

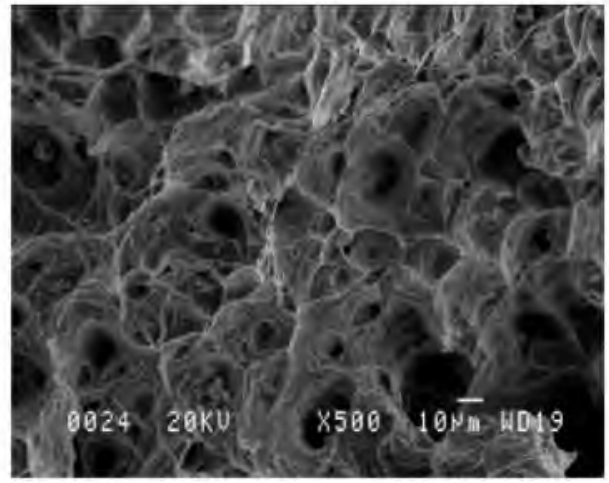

a)

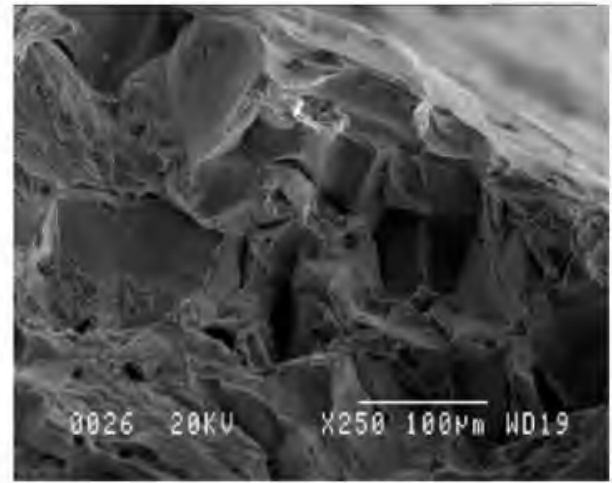

b)

Figure 5. Typical failures in slow tensile tests of: a) ATI 718Plus alloy as-annealed, b) Inconel 740.

These results suggest that slow strain rate tensile testing is a promising low cost screening tool for evaluation of the capability of different superalloys to resist high temperature ambient air environmental attack. By performing these tests in tandem with very fast deformation tensile tests for which no environmental effect was detected, the differences in the failure mode becomes readily apparent and thus a rapid assessment of the environmental behavior can be performed.

Fatigue Crack Growth Response of PM Superalloys

High temperature dwell fatigue crack growth behavior in superalloys is well known to be highly influenced by ambient environmental attack. This attack is typically associated with weakening of the grain boundary regions by oxidation resulting in an intergranular failure and pronounced increase in the fatigue crack growth rate [2]. Further, it has been shown [7] that dwell fatigue 
crack growth rates can vary by several orders of magnitude depending on the severity and the degree of intergranular failure.

Results for limited dwell fatigue crack growth tests of LSHR and Udimet 720 are compared in Fig. 6. One of the Udimet 720 specimens (345-L1) had been located adjacent to the edge of the oil-quenched disk rim and therefore was subjected to a high cooling rate, while the other specimen (345-L4) was more deeply embedded in this same disk and therefore had a slower cooling rate. Dwell fatigue crack growth rates (DFCGR) varied by over two orders of magnitude $(300 \mathrm{x})$ among the alloys and their varied heat treatment conditions. Among the PM alloys, with similar heat treatments, Udimet 720 had lower DFCGR than LSHR. This could be related to the higher $\mathrm{Cr}$ content or the different cooling paths from solution heat treatment of Udimet 720 , in comparison to LSHR. However, these variables were not separable among the PM alloys tested here.

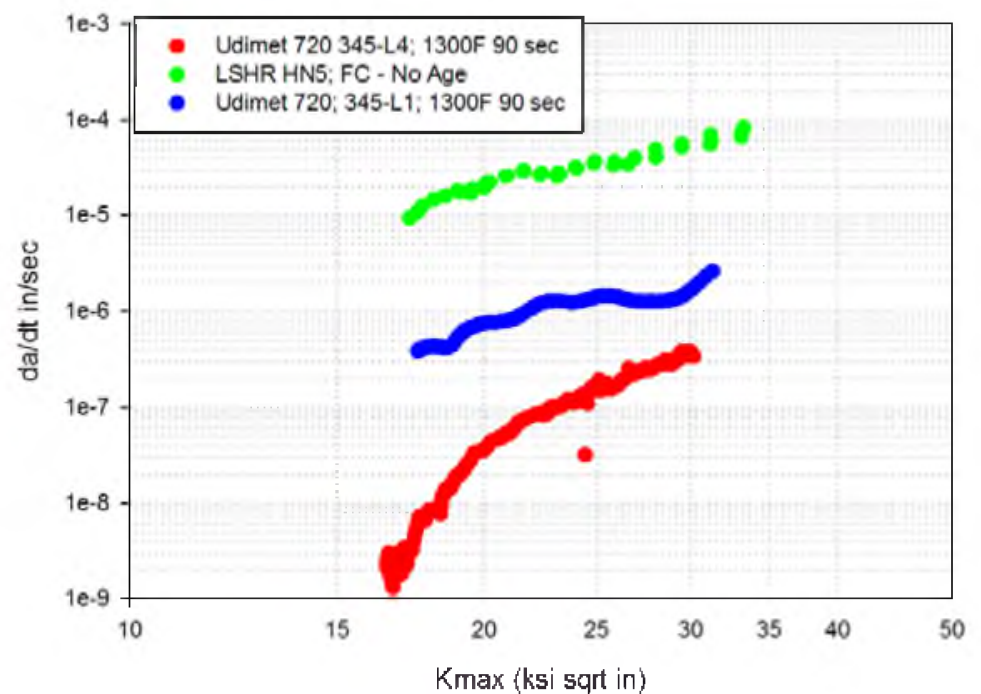

Figure 6. Comparison of crack growth rates with $90 \mathrm{~s}$ dwell at maximum stress, $704{ }^{\circ} \mathrm{C}$. Udimet 720 specimen $345-\mathrm{L} 1$ had a high cooling rate, 345 -L4 had a slower cooling rate.

\section{Fatigue Crack Growth Modes}

Typical dwell fatigue crack growth surfaces are shown in Fig. 7. Some intergranular cracking was generally observed in all of the tests, as extensively reported for other disk superalloys [1]. However, there were differences in degrees of intergranular cracking among the materials tested here. Materials having high DFCGR had more distinct and exclusive cracking along grain boundaries, and extensive secondary cracking of grain boundaries, as typified in Fig. 7a. Specimens with lower DFCGR had a fraction of transgranular cracking mixed in with the intergranularly cracked regions, with less secondary cracking, Fig. $7 \mathrm{~b}$ and 7c.

\section{Comparisons of Slow Tensile and Fatigue Crack Growth Results}

Comparisons of Figures 4 and 7 indicates the surface cracking for slow tensile tests and dwell fatigue crack growth tests looks very similar for the same materials. Materials having low fracture strains and high DFCGR had more clearly delineated intergranular cracking, while those with higher fracture strains and lower DFCGR had more transgranular cracking mixed in. Slow tensile fracture strain and reduction in area are plotted versus DFCGR at $25 \mathrm{MPa} \mathrm{m}^{0.5}$ in Fig. 8. Inelastic fracture strain observed in the low tensile tests was inversely correlated with $\log (\mathrm{DFCGR})$ for the tested materials. No significant correlation was observed for reduction in 
area and $\log (\mathrm{DFCGR})$. Overall, the results suggest that slow strain rate tensile tests could be useful in screening the intergranular cracking resistance of superalloys in air at low cost in material, specimen machining, and testing. Therefore, additional superalloys will be screened using these tests in the future.

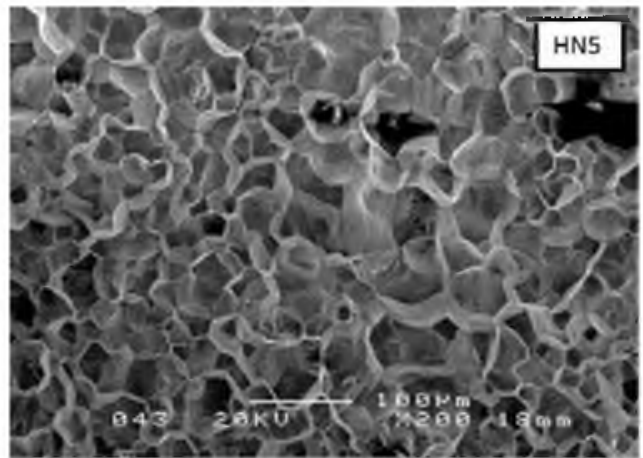

a)

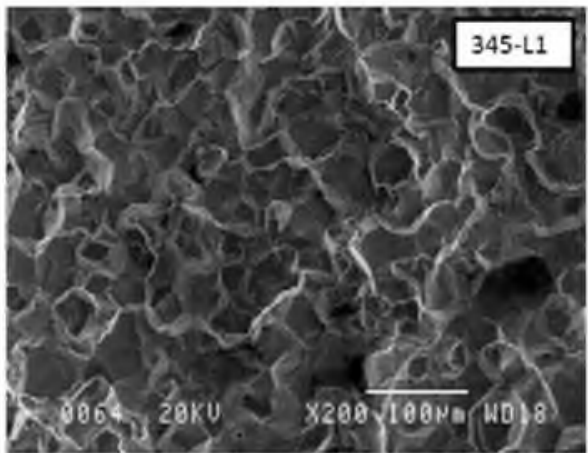

b)

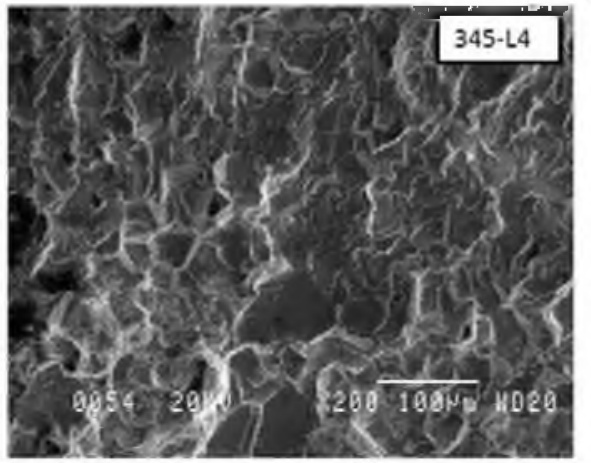

c)

Figure 7. Comparison of crack growth modes with $90 \mathrm{~s}$ dwell at maximum stress: a) LSHR fast DFCGR, b) Udimet 720, fast cooling rate, medium DFCGR, c) Udimet 720, slow cooling rate, slow DFCGR.

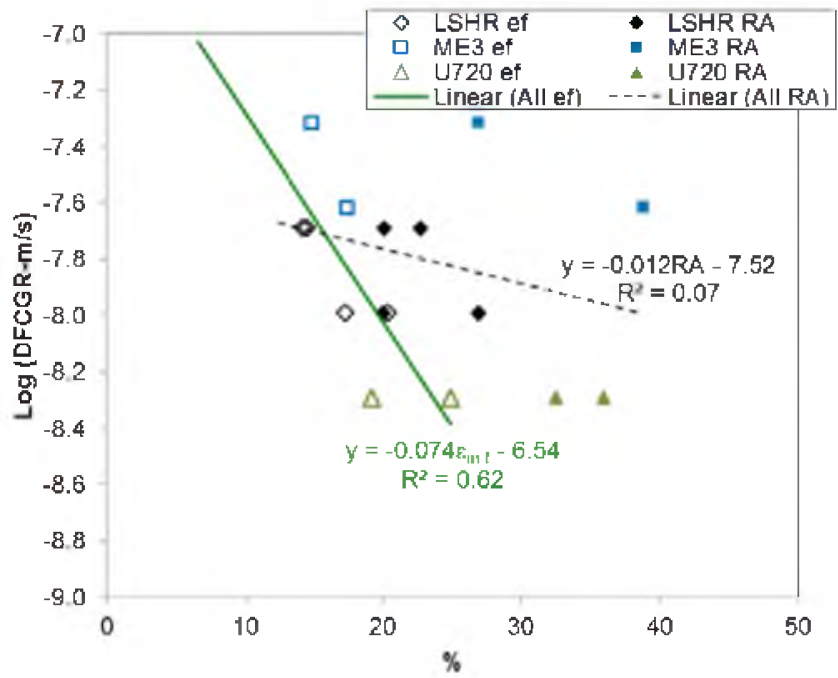

Figure 8. Comparisons of slow tensile inelastic fracture strain and reduction in area with DFCGR at $25 \mathrm{MPa}^{*} \mathrm{~m}^{0.5}$. 


\section{Summary and Conclusions}

Tensile tests were used to compare the effects of varied alloy composition and heat treatment on environment-assisted cracking of several PM and CW superalloys including ME3, LSHR, Udimet 720, ATI 718Plus alloy, Haynes 282, and Inconel 740. Slow and fast strain rate tensile tests were found to be a useful tool to compare propensities for intergranular crack initiation and growth. Intergranular surface cracking occurred in air for many of the alloys in slow strain rate tensile tests. More extensive intergranular surface cracking occurred for specimens having lower inelastic fracture strains. This occurred for materials in heat treatment conditions known to have high dwell fatigue crack growth rates.

It could be concluded from this work that:

1) Slow strain rate tensile testing is able to discriminate the environment-controlled failure mode response of the alloys and heat treatments tested in the study. The observed sensitivity to environmental degradation through the use of this test methodology makes the test a valuable, low cost screening tool.

2) The ductility of PM and CW superalloys can be limited at low tensile strain rates, due to environmentally assisted intergranular surface cracking.

3) The tensile strength of $\mathrm{PM}$ and $\mathrm{CW}$ superalloys can increase for high strain rates at temperatures as low as $704^{\circ} \mathrm{C}$, while maintaining good ductility.

\section{Acknowledgements}

ATI is acknowledged for supplying ATI 718Plus alloy. Lee Flower of Haynes International is acknowledged for supplying Haynes 282. Lewis Shumaker of Special Metals is acknowledged for supplying Inconel 740. Paul Browning of Solar Turbines is acknowledged for supplying Udimet 720 .

\section{References}

1. A. Pineau, S. D. Antolovich, "High Temperature Fatigue of Nickel-Base Superalloys-A Review With Special Emphasis on Deformation Modes and Oxidation", Engineering Failure Analysis, Vol. 17, 2009, pp. 2668-2697.

2. D. A. Woodford, "Gas Phase Embrittlement and Time Dependent Cracking of Nickel Based Superalloys", Energy Materials, Vol. 1, No. 1, 2006, pp. 59-79.

3. M.R. Bache, J.P. Jones, G.L. Drew, M.C. Hardy, N. Fox, "Environment and Time Dependent Effects on the Fatigue Response of an Advanced Nickel Base Superalloy," Int. J. Fatigue, V. 31, 2009, pp. 1719-1723.

4. J. Telesman, T. Gabb, Y. Yamada, L. Ghosn, D. Hornbach, N. Jayaraman, "Dwell Notch Low Cycle Fatigue Behavior of a Powder Metallurgy Nickel Disk Alloy", Superalloys 2012: 12 ${ }^{\text {th }}$ International Symposium on Superalloys, ed. E. S. Huron, R. C. Reed, M. C. Hardy, M. J. Mills, R. E. Montero, P. D. Portella, J. Telesman, TMS, Warrendale, PA, 2012, pp. 853-862.

5. K. R. Bain, M. L. Gambone, J. M. Hyzak, M. C. Thomas, "Development of Damage Tolerant Microstructures in Udimet 720", Superalloys 1988: $5^{\text {th }}$ International Symposium on Superalloys, ed. S. Reichman, D. N. Duhl, G. Maurer, S. ANtolovich, C. Lund, TMS, Warrendale, PA, 1988, pp. 13-22.

6. R. Molins, G. Hochstetter, J. C. Chassaigne, E. Andrieu, "Oxidation Effects on the Fatigue Crack Growth Behaviour of Alloy 718 at High Temperature,", Acta Mater., Vol. 45, No. 2, 1997, pp. 663-674. 
7. J. Telesman, T. P. Gabb, A. Garg, P. Bonacuse, J. Gayda, "Effect of Microstructure on Time Dependent Fatigue Crack Growth Behavior in a P/M Turbine Disk Alloy", Superalloys 2008, ed. R. C. Reed, K. A. Green, P. Caron, T. P. Gabb, M. G. Fahrmann, E. S. Huron, S. A. Woodard, TMS, Warrendale, PA, 2008, pp. 807-816.

8. T. P. Gabb, J. Telesman, P. T. Kantzos, A. Garg, "Effects of Temperature on Failure Modes for a Nickel-Base Disk Superalloy", J. Failure Analysis and Prevention, V. 7, Feb. 2007, pp. 56-65.

9. ASTM G129-00(2013), "Standard Practice for Slow Strain Rate Testing to Evaluate the Susceptibility of Metallic Materials to Environmentally Assisted Cracking," ASTM Book of Standards Volume 03.02, 2013.

10. J. J. deBarbadillo, S. K. Mannan, "Alloy 718 for Oilfield Applications", Proceedings of the $7^{\text {th }}$ International Symposium on Superalloy 718 and Derivatives, ed. E. A. Ott, J. R. Groh, A. Banik, I. Dempster, T. P. Gabb, R. Helmink, X. Liu, A. Mitchell, G. P. Sjoberg, A. Wusatowska-Sarnek, TMS, Warrendale, PA, 2010, pp. 255-270.

11. R. L. Kennedy, "Allvac 718Plus, Superalloy for the Next Forty Years", Superalloy 718, 625,706 , and Derivatives, ed. E. A. Loria, The Minerals, Metals \& Materials Society, 2005, pp. 1-14.

12. Inconel 740: Special Metals Corporation Publication No. SMC-090, 2004.

13. L. M. Pike, "Long Term Thermal Exposure of Haynes 282 Alloy," Proceedings of the $7^{\text {th }}$ International Symposium on Superalloy 718 and Derivatives, ed. E. A. Ott, J. R. Groh, A. Banik, I. Dempster, T. P. Gabb, R. Helmink, X. Liu, A. Mitchell, G. P. Sjoberg, A. Wusatowska-Sarnek, TMS, Warrendale, PA, 2010, pp. 645-660.

14. C. Sudbrack, S. Draper, T. Gorman, J. Telesman, T. Gabb, D. Hull, "Oxidation and the Effects of High Temperature Exposures on Notched Fatigue Life of an Advanced Powder Metallurgy Disk Superalloy", Superalloys 2012: 12 $2^{\underline{\underline{h}}}$ International Symposium on Superalloys, ed. E. S. Huron, R. C. Reed, M. C. Hardy, M. J. Mills, R. E. Montero, P. D. Portella, J. Telesman, TMS, Warrendale, PA, 2012, pp. 863-872.

15. T. P. Gabb, J. Telesman, P. T. Kantzos, J. W. Smith, "Effects of High Temperature Exposures on Fatigue Life of Disk Superalloys", Superalloys 2004, ed. K. A. Green, H. Harada, T. E. Howson, T. M. Pollock, R. C. Reed, J. J. Schirra, S. Walston, TMS, Warrendale, PA, 2004, pp. 269-274.ASTM G129-00, slow strain rate tensile test,

16. T. P. Gabb, J. Telesman, A. Garg, P. Lin, V. Provenzano, R. Heard, H. M. Miller, "Grain Boundary Engineering the Mechanical Properties of Allvac 718Plus Superalloy", Proceedings of the $7^{\text {th }}$ International Symposium on Superalloy 718 and Derivatives, ed. E. A. Ott, J. R. Groh, A. Banik, I. Dempster, T. P. Gabb, R. Helmink, X. Liu, A. Mitchell, G. P. Sjoberg, A. Wusatowska-Sarnek, TMS, Warrendale, PA, 2010, pp. 255-270. 